\title{
Spatio-temporal evolution of population and urbanization in the countries along the Belt and Road 1950-2050
}

\author{
LIU Haimeng ${ }^{1,2},{ }^{*}$ FANG Chuanglin ${ }^{1,2,3}$, MIAO Yi ${ }^{4}$, MA Haitao ${ }^{1}$, ZHANG Qiang ${ }^{1}$, \\ ZHOU Qiang ${ }^{1,2}$ \\ 1. Institute of Geographic Sciences and Natural Resources Research, CAS, Beijing 100101, China; \\ 2. College of Resources and Environment, University of Chinese Academy of Sciences, Beijing 100049, China; \\ 3. Institute of Economics, Xinjiang University, Urumqi 830046, China; \\ 4. College of Geography and Environment, Shandong Normal University, Jinan 250014, China
}

\begin{abstract}
This paper uses data for the period 1950-2050 compiled by the United Nations Population Division together with methods including spatial autocorrelation analysis, hierarchical cluster analysis and the standard deviational ellipse, to analyze the spatio-temporal evolution of population and urbanization in the 75 countries located along the routes of the Silk Road Economic Belt and the 21st-century Maritime Silk Road, to identify future population growth and urbanization hotspots. The results reveal the following: First, in 2015, the majority of Belt and Road countries in Europe, South Asia and Southeast Asia had high population densities, whereas most countries in Central Asia, North Africa and West Asia, as well as Russia and Mongolia, had low population densities; the majority of countries in South Asia, Southeast Asia, Central Asia, West Asia and North Africa had rapid population growth, whereas many countries in Europe had negative population growth; and five Belt and Road countries are in the initial stage of urbanization, 44 countries are in the acceleration stage of urbanization, and 26 are in the terminal stage of urbanization. Second, in the century from 1950 to 2050 , the mean center of the study area's population is consistently located in the border region between India and China. Prior to 2000, the trajectory of the mean center was from northwest to southeast, but from 2000 it is on a southward trajectory, as the population of the study area becomes more concentrated. Future population growth hotspots are predicted to be in South Asia, West Asia and Southeast Asia, and hotspot countries for the period 2015-2030 include India, China, Pakistan and Indonesia, though China will move into negative population growth after 2030. Third, the overall urban population of Belt and Road countries increased from $22 \%$ in 1950 to $49 \%$ in 2015 , and it is expected to gradually catch up with the world average, reaching $64 \%$ in 2050 . The different levels of urbanization in different countries display significant spatial dependency, and in the hundred-year period under con-
\end{abstract}

Received: 2017-09-10 Accepted: 2017-10-26

Foundation: The Strategic Priority Research Program of the CAS, Pan-Third Pole Environment Study for a Green Silk Road (Pan-TPE), No.XDA20040400; Key Deployment Project of the CAS, No.ZDRW-ZS-2016-6-2

Author: Liu Haimeng (1989-), PhD, specialized in urban geography, regional planning, and coupled human and natural systems. E-mail: haimengliu@163.com

"Corresponding author: Fang Chuanglin (1966-), PhD and Professor, E-mail: fangcl@igsnrr.ac.cn 
sideration, this dependency increases before eventually weakening. Fourth, between 2015 and 2030, urban population hotspots will include Thailand, China, Laos and Albania, while Kuwait, Cyprus, Qatar and Estonia will be urban "coldspots." Fifth, there were 293 cities with populations over 1 million located along the Belt and Road in 2015, but that number is expected to increase to 377 by 2030 . Of those, 43 will be in China, with many of the others located in India, Indonesia and the eastern Mediterranean.

Keywords: Belt and Road; population; urbanization; population migration; spatio-temporal evolution; China

\section{Introduction}

In 2013, Chinese President Xi Jinping announced a major initiative to build a Silk Road Economic Belt and a 21st Century Maritime Silk Road (the Belt and Road). This led to the establishment of the Silk Road Fund and the Asian Infrastructure Investment Bank, as well as mention of the Belt and Road in Resolution A/71/9 of the 71st General Assembly of the United Nations, which helped bring it to the attention of the international community (Ferdinand, 2016; Zhao, 2016). The Belt and Road Initiative aims to encourage inclusive globalization, promote economic prosperity and peaceful development in countries along both routes, strengthen interactions between cultures, and establish open, inclusive and balanced regional economic cooperation, so as to realize the United Nations' 2030 Agenda for Sustainable Development (Hong, 2016; Liu et al., 2017).

Many countries located along the Belt and Road are currently experiencing rapid population growth and are in the acceleration stage of urbanization. Healthy population growth and urbanization are basic guarantees and a source of vitality for policy communication, infrastructure link-ups, trade flows, capital financing and people-to-people exchanges between countries. Population concentration and migration, the pace of urbanization, and the size and distribution of core cities all directly affect the future economic performance and social stability of countries and regions. As a result, the spatio-temporal evolution of population and urbanization in Belt and Road countries is a key area of research, as it is of great practical significance for promoting the development of the "six Belt and Road economic corridors"1 and helping Chinese enterprises to decide whether to invest in Belt and Road countries.

The Belt and Road Initiative is a major long-term internal and diplomatic strategy for China, and a great deal of quantitative empirical research has been carried out on this topic in recent years, resulting in the publication of a number of studies in Chinese by Chinese scholars. Of these, the majority have looked at economic and trade ties between China and Belt and Road countries. This include studies on the spatio-temporal pattern of economic development in Belt and Road countries (Pan et al., 2016); the pattern (Zou and Liu, 2016), cost (Liu and Cai, 2016) and efficiency of (Tian and Xu, 2016), and influencing factors on (Liang and $\mathrm{Wu}, 2016$ ), trade between China and Belt and Road countries; potential, efficiency and locations for Chinese investment in Belt and Road countries (Chen and Guo, 2016; Fan et al., 2016); and on agricultural exports (Sun and Li, 2016) and cross-border e-commerce (Liu et al., 2016). There have also been studies on the energy resources (Howard and Howard, 2016; Guo et al., 2015), ecological environment (Li et al., 2014), infra-

1 The six major economic corridors are China-Mongolia-Russia, the New Eurasian Continental Bridge, China-Central Asia-West Asia, China-Indochina Peninsula, China-Pakistan, and Bangladesh-China-India-Burma. 
structure (Yang et al., 2016; Zhang et al., 2016), social risks (Zhao et al., 2016), geopolitics (Zeng, 2016), information technology (Cheng et al., 2016) and regional cultures (Zhu, 2016) of Belt and Road countries. Generally speaking, quantitative studies on these countries are still fragmented and preliminary, and their time scales are short. There is particularly a lack of spatio-temporal two-dimensional systems research on population and urbanization development covering Belt and Road regions.

In light of this, this paper uses data for a 100-year period (1950-2050), covering the past, present and future, compiled by the United Nations (UN) Population Division, together with methods including spatial autocorrelation analysis, hierarchical cluster analysis, the standard deviational ellipse and the gravity model of migration, to analyze for the first time the spatio-temporal evolution of population and urbanization in the 75 countries located along the Belt and Road, and to identify future population growth and urbanization hotspots. This will provide important theoretical and practical support to economic, trade and cultural cooperation between China and relevant countries, as well as to exporting China's urbanization model and experience, and helping Chinese enterprises become more global.

\section{Data and methods}

\subsection{Data sources}

The Belt and Road are open and inclusive international regional economic cooperation networks. Their spatial ranges are not fully defined, and countries that wish to be part of them are free to join (Liu, 2015). Based on the "Vision and Actions on Jointly Building the Silk Road Economic Belt and 21st Century Maritime Silk Road" released by the Chinese government in 2015, this paper divides the 75 Belt and Road countries from the six economic corridors in the study area into seven sub-regions: Southeast Asia, South Asia, West Asia, Central Asia, Europe, North Africa and China-Mongolia-Russia (see Table 1). The statistics on total population, population density, population growth rate, net number of migrants, net migration rate, urban population and number of megacities of more than one million people used in this study are from the UN Population Division. Statistics for the period 1950-2015

Table 1 Major countries in the Belt and Road

\begin{tabular}{|c|c|c|}
\hline Region & Countries & Number \\
\hline China-Mongolia-Russia & China, Mongolia, Russia & 3 \\
\hline Southeast Asia & $\begin{array}{l}\text { Singapore, Malaysia, Indonesia, Myanmar, Laos, Thailand, Cambodia, Vietnam, } \\
\text { Philippines, Brunei, East Timor }\end{array}$ & 11 \\
\hline South Asia & India, Pakistan, Bangladesh, Afghanistan, Sri Lanka, Maldives, Nepal, Bhutan & 8 \\
\hline West Asia & $\begin{array}{l}\text { Iran, Iraq, Turkey, Syria, Jordan, Lebanon, Israel, Palestine, Saudi Arabia, } \\
\text { Yemen, Oman, United Arab Emirates, Qatar, Kuwait, Bahrain, Georgia, Arme- } \\
\text { nia, Azerbaijan, Cyprus }\end{array}$ & 19 \\
\hline Central Asia & Kazakhstan, Uzbekistan, Tajikistan, Turkmenistan, Kyrgyzstan & 5 \\
\hline Europe & $\begin{array}{l}\text { Ukraine, Belarus, Moldova, Poland, Lithuania, Latvia, Estonia, Czech Republic, } \\
\text { Slovakia, Hungary, Slovenia, Croatia, Bosnia \& Herzegovina, Montenegro, } \\
\text { Romania, Bulgaria, Serbia, Albania, Macedonia, Greece, Italy, Germany, Neth- } \\
\text { erlands }\end{array}$ & 24 \\
\hline North Africa & Egypt, Algeria, Libya, Morocco, Tunisia & 5 \\
\hline
\end{tabular}


are historical data, but statistics for the period 2015-2050 are projections of the UN Population Division ${ }^{2}$.

\subsection{Research methods}

\subsubsection{Spatial autocorrelation analysis}

According to Waldo Tobler's first law of geography, "everything is related to everything else, but near things are more related than distant things", which means near things have greater spatial dependence. Global Moran's I can be used to measure the autocorrelation of regions as a whole and identify clustering based on locations and attribute values (Fang et al., 2015). The formula is given at (1) below, where $\bar{x}$ is the mean observed value of all $k$ positions (regions), $W_{i j}$ is the spatial weights matrix, $x_{i}$ represents the observed value of the $i$-th position (region), and $i \neq j$. The Global Moran's $I$ score is usually between [-1, 1]. A score of 0 indicates no correlation; a score greater than 0 indicates a positive correlation and indicates spatial clustering of similar attribute values; a score of less than 0 indicates negative correlation. The significance of spatial autocorrelation can be verified by the normalized statistic $\mathrm{Z}$ value, the formula for which is given at (2) below.

$$
\begin{gathered}
I=\frac{k \sum_{i=1}^{K} \sum_{j=1}^{K} W_{i j}\left(x_{i}-\bar{x}\right)\left(x_{j}-\bar{x}\right)}{\sum_{i=1}^{K} \sum_{j=1}^{K} W_{i j} \sum_{i=1}^{K}\left(x_{i}-\bar{x}\right)^{2}} \\
Z=\frac{I-E(I)}{\sqrt{\operatorname{VAR}(I)}}
\end{gathered}
$$

\subsubsection{Hierarchical cluster analysis}

Hierarchical cluster analysis (HCA) is based on the principle of clustering of items and is used for one or more indicators of a geographical system, to merge and sort geographical elements. During cluster analysis, after determining the geographical elements and their indicator data, it is necessary, first, to standardize the data, and then calculate spatial distances, to form a distance matrix. In this paper, Euclidean distance is used as the distance metric, which is expressed in formula (3) below, where $P_{i}$ and $P_{k}$ are the spatial positions of sub-regions $i$ and $k$, and $n$ is the number of sub-regions.

$$
d_{i k}=\sqrt{\sum_{\mathrm{n}=1}^{\mathrm{N}}\left(p_{i n}-p_{k n}\right)^{2}}
$$

Second, an appropriate classification method was chosen. The most commonly used methods include nearest neighbor, furthest neighbor, centroid method and Ward's method. Ward's method was selected for this study for its excellent results and wide application.

\subsubsection{Spatio-temporal evolution analysis}

Spatio-temporal evolution analysis mainly uses the standard deviational ellipse and spatial mean center, as well as cartograms (Hennig, 2013), parallel coordinates and other visualizetion methods, to analyze evolutionary patterns in different spatial and temporal dimensions.

\footnotetext{
${ }^{2}$ https://esa.un.org/unpd/wpp/Download/Standard/Population/
} 
Of these, the first two are mainly used to depict the spatial mean center and degree of dispersion of relevant indicators at the national scale:

(1) Standard deviational ellipse is a common method of analyzing the spatial distribution features of a partial or whole dataset (Song and Yang, 2016). The standard deviations of the long axis and the short axis represent the maximum and minimum direction of diffusion, respectively, and the elliptical area reflects the degree of spatial dispersion of an element and its indicators. One standard deviation will cover $60 \%$ of the spatial range, so the smaller the area the more concentrated its distribution. In this paper, a distribution of one standard deviation is used in the calculation.

(2) Spatial mean center statistics is based on the spatial location of features within a region as well as the mean center of their indicators (Tao et al., 2015). In a specific calculation, it often represents a feature using the center point of a part or whole, and its indicator is used as its weight to get the center location.

(3) Spatial mean center and standard deviational ellipse can be achieved using the spatial statistical analysis tool in ArcGIS10.2.

\section{Analysis of population and urbanization along the Belt and Road}

\subsection{Population distribution}

In 2015, the 75 Belt and Road countries had a total population of 4.83 billion, accounting for $65.98 \%$ of the world's population (7.33 billion). Figure 1 shows a cartogram of the total populations of the Belt and Road countries, and Figure 2 shows their population densities. From these two maps, it can clearly be seen that the population distribution of countries along the Belt and Road is very uneven. Seven countries have a population of over 100 million, namely China, India, Indonesia, Pakistan, Bangladesh, Russia and the Philippines. The total population of these seven countries is over two-thirds the total population of the study area. In comparison, the total population of the next 40 largest Belt and Road countries by population account for only $3.81 \%$ of the study area.

Population density reflects population concentration but also often represents the size of an area's market. In 2015, worldwide human population density was 56.49 people per $\mathrm{km}^{2}$, but it averaged 88.26 per $\mathrm{km}^{2}$ in the Belt and Road countries, and 146.57 per km² in China. As Figure 2 shows, the population densities of most countries in Europe, South Asia and Southeast Asia are relatively high, but relatively low in Central Asia, North Africa, West Asia, Russia and Mongolia. Singapore has the highest population density, with 8005.34 per $\mathrm{km}^{2}$; Bahrain, Bangladesh and Maldives are the only other countries with population densities above 1000 per $\mathrm{km}^{2}$. Mongolia, Libya, Russia and Kazakhstan all have population densities below 10 per $\mathrm{km}^{2}$.

Between 2010 and 2015, the average population growth rate of Belt and Road countries was $1.13 \%$, slightly lower than the world average population growth rate of $1.15 \%$. Of the Belt and Road countries, 15 had negative population growth, as shown in Figure 3. These countries were mainly in Europe. Of the seven countries with populations over 100 million, only Russia had a negative growth rate. Due to its long-term family planning policies, China had a growth rate of just $0.6 \%$. Some countries in South Asia and Southeast Asia are not 


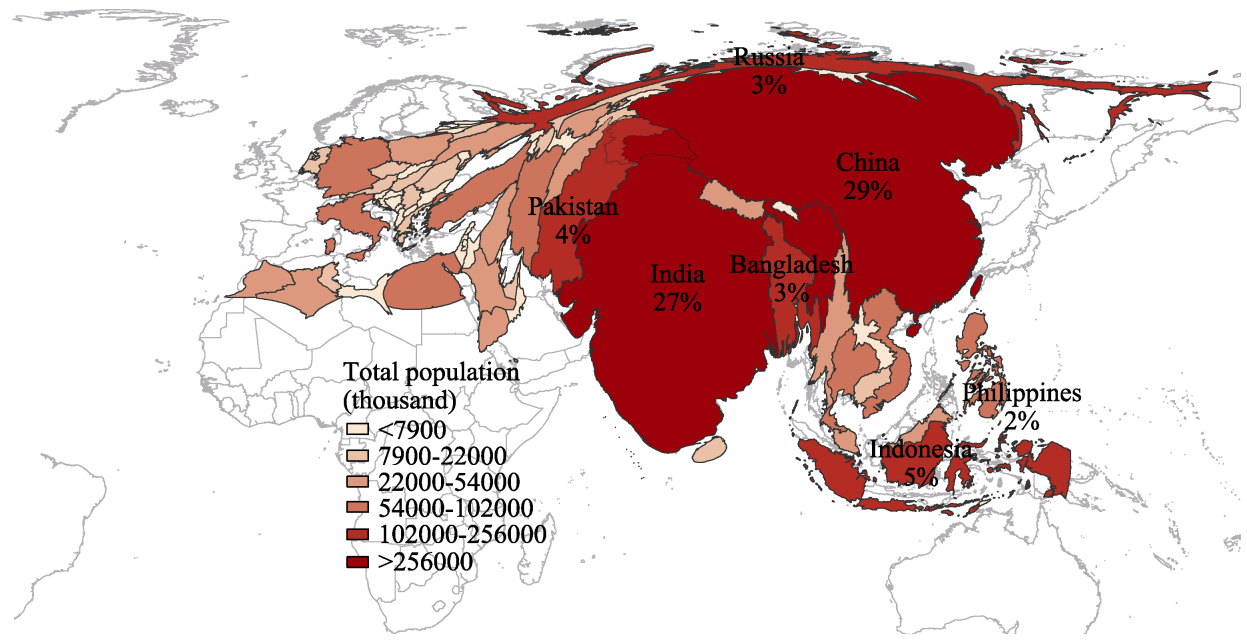

Figure 1 Cartogram showing populations of Belt and Road countries

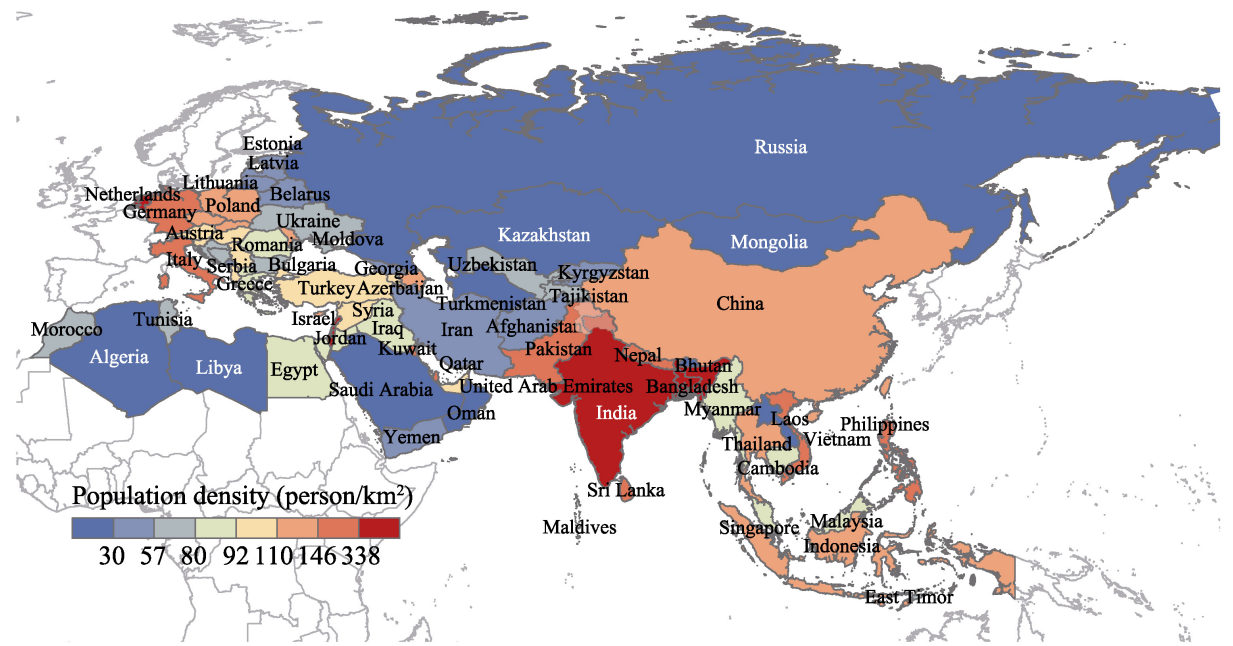

Figure 2 Population densities of Belt and Road countries in 2015

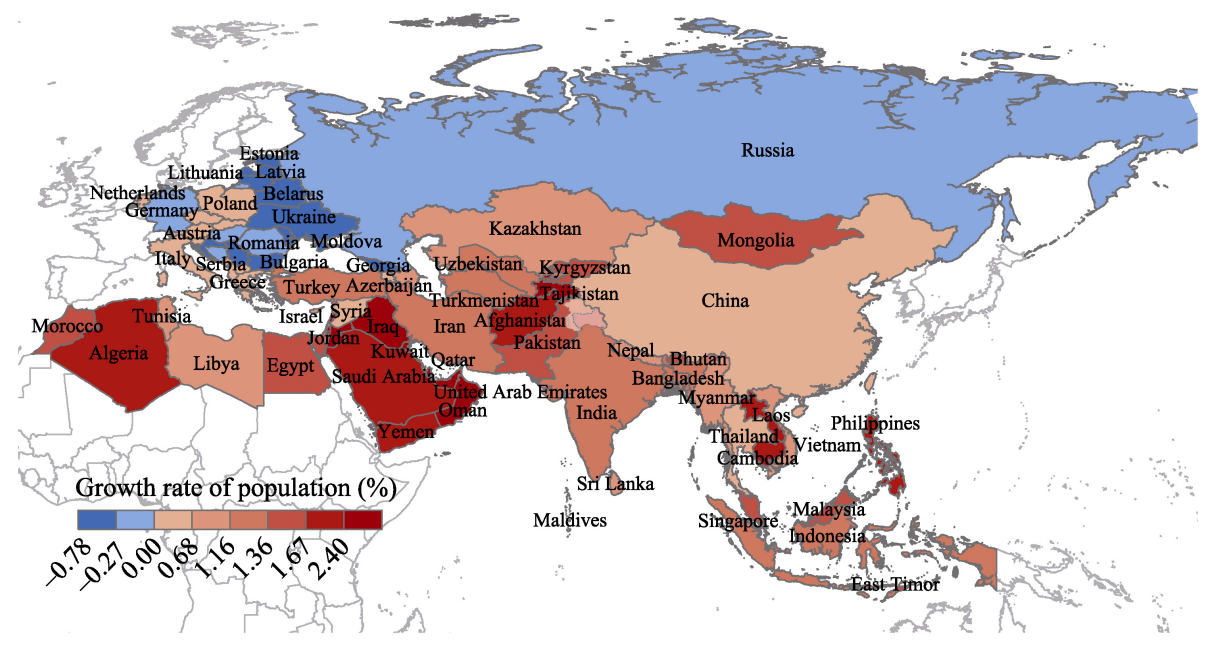

Figure 3 Population growth rate of Belt and Road countries 2010-2015 
only densely populated, but are still experiencing rapid population growth. Population bases of countries in Central Asia, West Asia and North Africa are small, but most are in the early stages of industrialization so they are currently experiencing rapid population growth. Of them, Oman and Qatar have the fastest population growth rates of $7.9 \%$ and $5.9 \%$, respectively.

\subsection{Urbanization}

In 2015, 54\% of the world's population lived in urban areas. The average for Belt and Road countries was slightly lower at $53.5 \%$, and China's urban population was slightly higher at $55.6 \%$. According to Northam's urbanization theory (Chen et al., 2014), the clear majority (44) of these 75 countries are in the acceleration stage of urbanization; 26 countries have urban populations of $70 \%$ or higher and are in the terminal stage of urbanization; and only five countries (Sri Lanka, Nepal, Cambodia, Afghanistan and Tajikistan) have urban populations below $30 \%$, and are in the initial stage of urbanization.

Figure 4 shows that, of the Belt and Road countries, West Asian countries had the highest urban populations as a proportion of their totals, and South Asian countries had the lowest. Singapore had the highest urban population at $100 \%$. The Netherlands and West Asian countries including Qatar, Kuwait and Israel had urban populations of over 90\%. Other West Asian countries, such as Bahrain, Lebanon, the UAE, Jordan and Saudi Arabia also had relatively high urban populations. In contrast, South Asian countries of Sri Lanka and Nepal had the lowest urban populations of just $18.4 \%$ and $18.6 \%$, respectively. Levels of urbanization in other South Asian countries, including India, Bangladesh, Pakistan and Bhutan, were all below 40\%. The Central Asian countries of Tajikistan, Kyrgyzstan and Uzbekistan all have urban populations below $36 \%$ of their totals.

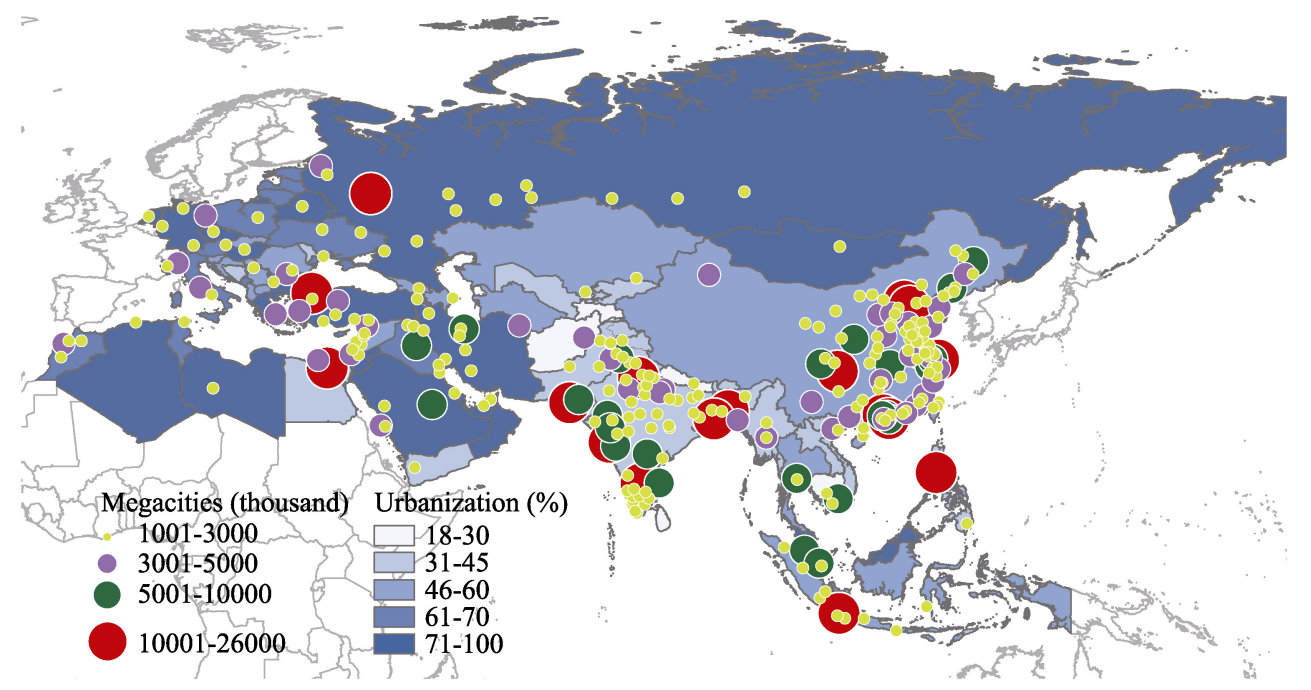

Figure 4 Urbanization and distribution of megacities in Belt and Road countries in 2015

Figure 4 also shows the locations of the 293 cities in Belt and Road countries with populations over 1 million each. These countries are mainly located in eastern China, South Asia, the northeastern coast of the Mediterranean and Southeast Asia. Of these 293 cities, 17 have 
populations of more than 10 million (including six in China), 25 have populations of 5-10 million (including 11 in China), and 251 have populations of 1-5 million, forming a pyramidal city scale structure.

\subsection{Cluster analysis of population and urbanization}

Cluster analysis was carried out to further understand the population and urbanization trends of Belt and Road countries. The five indicators of total population, urban population, population density, population growth rate and net migration rate were used to conduct a hierarchical cluster analysis and group the 75 Belt and Road countries into clusters. The data was first standardized to eliminate the variable of size. Ward's clustering method was used and Euclidean distance selected as the distance metric. In the end, the countries were divided into seven groups. The countries and features of each group are given in Table 2. China and India were grouped together due to their similarities in indicators including total population and urban population. The other Belt and Road countries have certain differences with China.

Table 2 Results of cluster analysis of population and urbanization of Belt and Road countries

\begin{tabular}{|c|c|c|}
\hline Group & Country names & International distribution and features \\
\hline 1 & $\begin{array}{l}\text { Armenia, Montenegro, Poland, Czech Republic, Italy } \\
\text { Austria, Bulgaria, Ukraine, Belarus, Hungary, Esto- } \\
\text { nia, Latvia, Lithuania, Russia, Germany, Greece, } \\
\text { Netherlands, Lebanon }\end{array}$ & $\begin{array}{l}\text { Countries are mainly European and mainly lo- } \\
\text { cated in the northwest part of the study area. They } \\
\text { have relatively high urban populations, low popu- } \\
\text { lation growth rates, high population densities and } \\
\text { average total populations. }\end{array}$ \\
\hline 2 & $\begin{array}{l}\text { Slovakia, Macedonia, Thailand, Slovenia, Albania, } \\
\text { Moldova, Bosnia and Herzegovina, Romania, Serbia, } \\
\text { Croatia, Georgia }\end{array}$ & $\begin{array}{l}\text { Countries are mainly in Europe, with a small } \\
\text { number located on the east coast of the Black Sea } \\
\text { and in SE Asia. They have similar features to the } \\
\text { first group, but low urban populations as a per- } \\
\text { centage of their totals and relatively small popula- } \\
\text { tions. }\end{array}$ \\
\hline 3 & $\begin{array}{l}\text { Tunisia, Cyprus, Morocco, Kazakhstan, Azerbaijan, } \\
\text { Turkmenistan, Indonesia }\end{array}$ & $\begin{array}{l}\text { Countries are mainly in Central Asia and North } \\
\text { Africa, with one located in the Malay islands. } \\
\text { They have relatively high population growth rates } \\
\text { and average urban population levels. }\end{array}$ \\
\hline 4 & $\begin{array}{l}\text { Kuwait, Oman, Palestine, Iraq, Syria, Mongolia, } \\
\text { Malaysia, } \\
\text { Algeria, Iran, Brunei, Turkey, Jordan, Libya, Israel, } \\
\text { Qatar, Bahrain, Saudi Arabia, UAE }\end{array}$ & $\begin{array}{l}\text { Countries are mainly in West Asia and North } \\
\text { Africa. They have relatively high urban popula- } \\
\text { tion levels, population densities, net migration } \\
\text { rates and population growth rates. }\end{array}$ \\
\hline 5 & Singapore & $\begin{array}{l}\text { Located on the southern tip of the Malay Penin- } \\
\text { sula. It has very high urban population, population } \\
\text { density and net migration rate. }\end{array}$ \\
\hline 6 & China, India & $\begin{array}{l}\text { Located in East Asia and South Asia, respectively. } \\
\text { They have very large total populations, high } \\
\text { population densities and high outward migration. }\end{array}$ \\
\hline 7 & $\begin{array}{l}\text { Nepal, Sri Lanka, Cambodia, Uzbekistan, Bhutan, } \\
\text { Myanmar, Vietnam, Bangladesh, Tajikistan, Afghani- } \\
\text { stan, Yemen, Kyrgyzstan, Laos, Timor-Leste, Egypt, } \\
\text { Philippines, Pakistan, Maldives }\end{array}$ & $\begin{array}{l}\text { Scattered distribution. Relatively low population } \\
\text { densities, urban populations and net migration } \\
\text { rates, but relatively high population growth. }\end{array}$ \\
\hline
\end{tabular}

\section{Spatio-temporal evolution of population and urbanization in Belt and Road countries}

\subsection{Spatial-temporal evolution characteristics of population growth}

The total population of the 75 Belt and Road countries remained at between $67 \%$ and $68 \%$ 
of the world's total population during the 60-year period 1950-2010, but by 2015 it had fallen slightly to $66 \%$. According to the UN Population Division's forecast, this proportion will continue to decline, falling to $63 \%$ by 2030 . By 2050 , it is estimated that the rate of population growth in Belt and Road countries as a whole will be $0.11 \%$, much lower than the world's population growth rate of $0.50 \%$, and by that time the population of Belt and Road countries will only be $59 \%$ of the world's total. Figure 5 shows that the total population of the 75 Belt and Road countries was 1.7 billion in 1950, but due to rapid population growth in China and regions such as South Asia and Southeast Asia from about 1965 onwards, the total population of Belt and Road countries had increased to 4.83 billion by 2015. According to the UN Population Division's forecast (Dashed box in Figure 5), South Asia, West Asia and Southeast Asia will be population growth hotspots in the future, and by 2050 the total population of Belt and Road countries will reach 5.63 billion. In the century from 1950 to 2050, the total populations of Europe, Russia and Mongolia will have changed relatively little, and population growth in Central Asia, West Asia and North Africa will have gradually accelerated. But because of the small base populations of those regions, their total population as an overall proportion of Belt and Road countries will still be very small by 2050 .

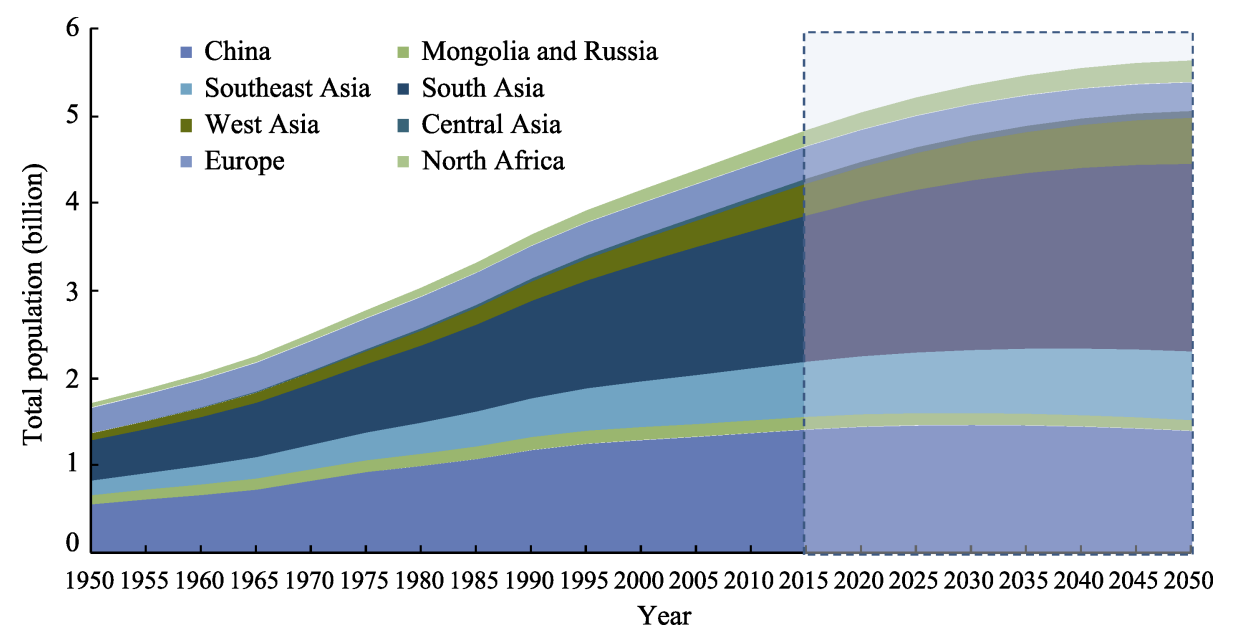

Figure 5 Area stacking diagram showing changes in total population of Belt and Road regions 1950-2050

Looking at individual countries, according to the UN forecast, from 2015 onward, China's population growth will decline significantly until it reaches negative growth in 2030 . But the implementation of China's two-child policy means the accuracy of this forecast is highly uncertain. India is another Belt and Road country with a very large total population. In 1950, its population accounted for $22 \%$ of the population of the study area, but it accounted for $26 \%$ by 2015 , and by 2050 it is expected to account for $28 \%$, reaching 1.62 billion, which will give it the largest population in the study area. Russia's population has remained around 100-150 million for a long time, but since 1995 it has experienced negative population growth. Throughout the 1970s, '80s and '90s, Pakistan's annual population growth rate exceeded 3\%, helping it to grow rapidly from 37 million in 1950 to 188 million by 2015, and it is due to reach 221 million by 2050 according to the UN's forecast. The countries of Bangladesh, Indonesia and the Philippines, all of which already have populations over 100 million, are expected to continue to grow rapidly in the next 35 years. 
Figure 6 shows the population mean center and standard deviational ellipse of Belt and Road countries for the period 1950-2050. The population mean center of the study area is consistently located in the border region between China, India and Nepal. Before 2000, the trajectory of the mean center was from northwest to southeast, but from 2000 the mean center is on a southward trajectory. This change in trajectory is closely connected to changes in the total populations of China and South Asian countries. In addition, the long and short axes of standard deviational ellipses for population have remained basically stable, but the elliptical area is gradually narrowing and moving southward, which indicates that the overall population of Belt and Road countries is becoming more concentrated. This agglomeration is mainly in South Asian countries.

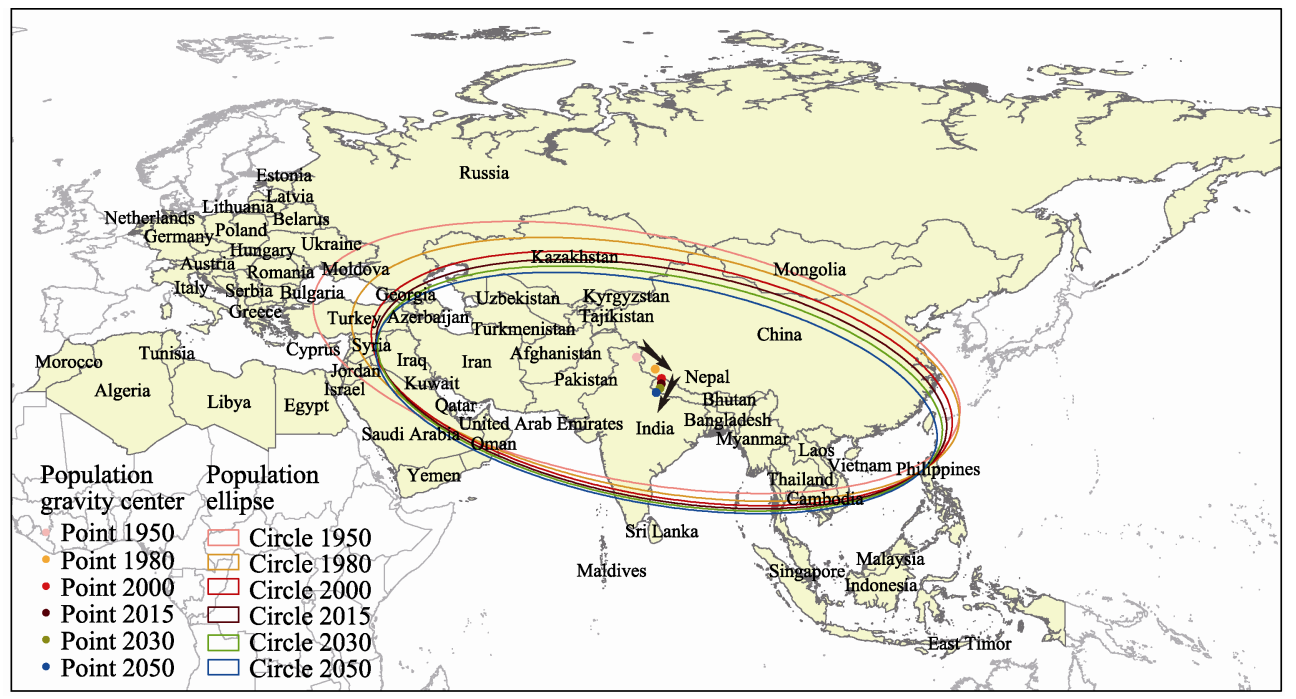

Figure 6 Evolution of the population mean centre and standard deviational ellipse for Belt and Road countries 1950-2050

\subsection{Spatio-temporal evolution characteristics of urbanization}

Level of urbanization is an important indicator of regional socio-economic development. It can be seen from Figure 7 that in the period 1950-2015 changes in the level of urbanization in the Belt and Road regions basically mirrored changes in the worldwide level, but it constantly remained below the world average, increasing from $22 \%$ in 1950 to $49 \%$ in 2015 . In the future (Dashed box in Figure 7), the urban population as a proportion of the total population will gradually draw level with the world average as it reaches $64 \%$ in 2050 . China reached the average level of urbanization for Belt and Road countries in 2005, and it surpassed the world average level in 2015. By 2050, its urban population is expected to reach $76 \%$.

We selected 23 typical Belt and Road countries based on population and their stage of economic development as well as using the averages for the world and the Belt and Road regions, and ordered them by their level of urbanization in 2015. The use of parallel coordinates vividly demonstrates the changes in their urbanization rate from 1950 to 2050 (see Figure 8). Each colored line in the graph represents a year (red represents 2015, for example), and each vertical line indicates a country or region. The more scattered a line's distri- 
bution is vertically, the greater the change in the level of urbanization. If the colored lines cross, it means a country's level of urbanization fell. It can be seen that the urban populations of China, Mongolia, Iran, Turkey, Malaysia, Belarus and Saudi Arabia change significantly during the century, with an average increase of over 60 percentage points, and with all having urban populations over $70 \%$ and reaching the terminal stage of urbanization by 2050 . Kazakhstan, Poland, Italy, Russia, Germany, Greece, the Netherlands, Egypt and Israel all already had levels of urbanization above $30 \%$ in 1950 as they entered the acceleration stage of urbanization. However, it is worth noting that urbanization in Kazakhstan and Egypt slows over the study period, and their levels of urbanization are not expected to reach $70 \%$ by 2050 . Because of their large base populations, the pace of urbanization in India, Bangladesh, Pakistan and the Philippines is also relatively slow, and their levels of urbanization are expected to remain below $60 \%$ by 2050 .

From the intersecting lines in Figure 8 it can be seen that counterurbanization occurred in Kazakhstan, the Philippines and Egypt between 1990 and 2015. The main reason for this in

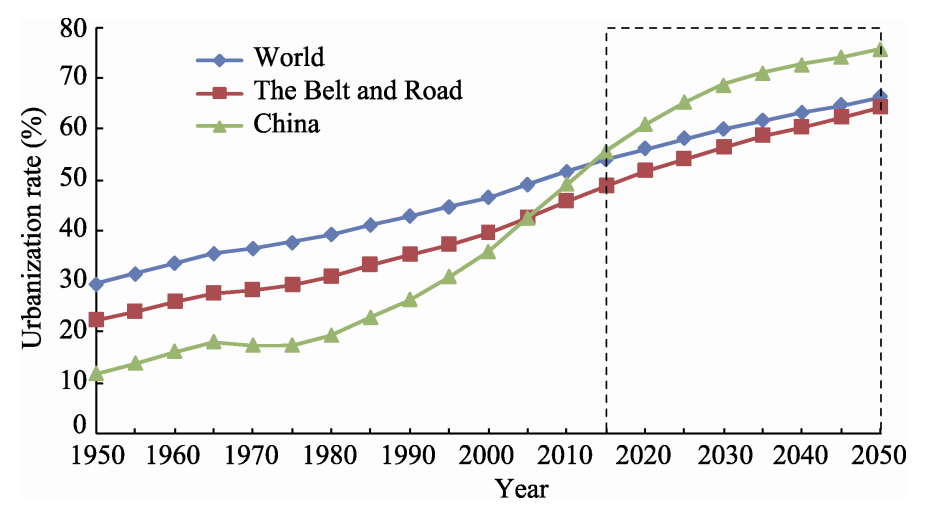

Figure 7 Urban population (\% of total) of the Belt and Road regions 1950-2050

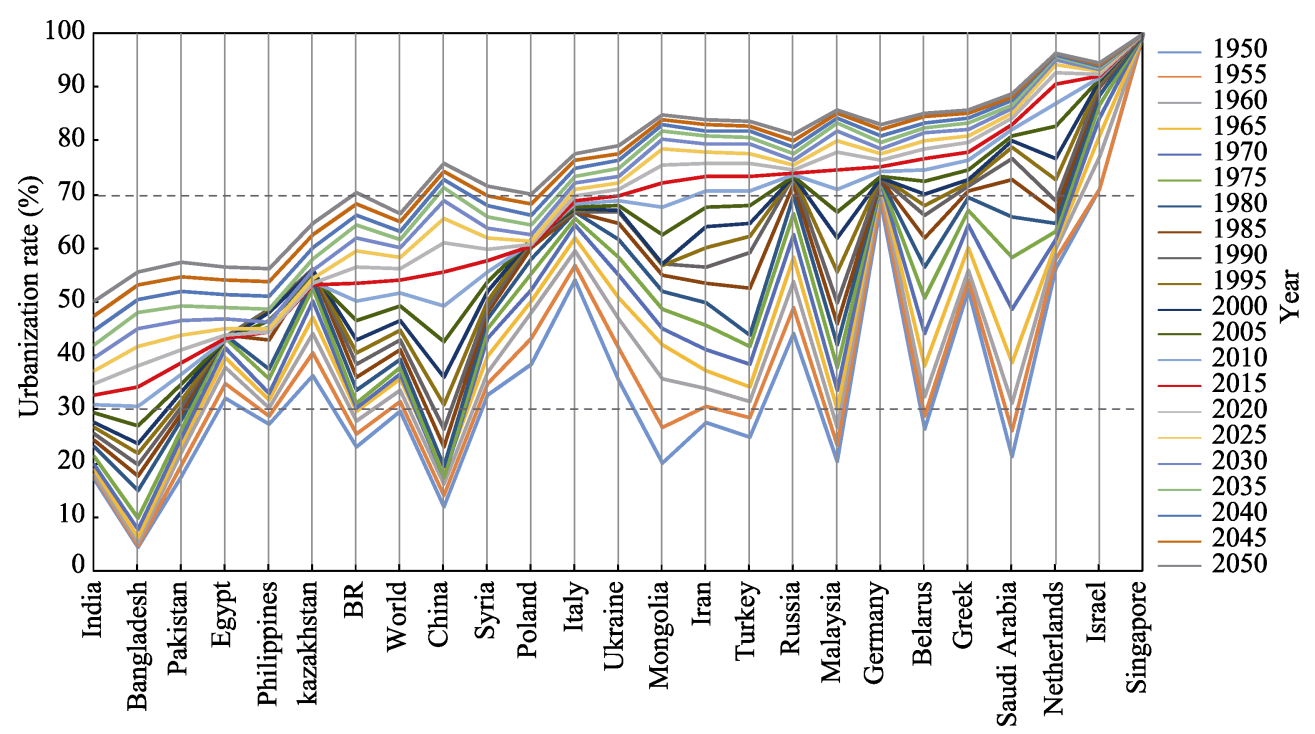

Figure 8 Parallel coordinates of urbanization for typical Belt and Road countries 1950-2050 Note: BR means the Belt and Road countries 
Kazakhstan was the decline in the urban economy following the country's departure from the Soviet Union in the 1990s, which caused people to move out of the cities. In the Philippines, it was due to economic and political crises in the late 1980s, which led to economic recession and the country getting caught in the middle-income trap. China also experienced a decade of counterurbanization from 1965 to 1975 due to the implementation of the Up to the Mountains and Down to the Countryside Movement. Poland's urban population has also declined slightly over the past almost 10 years, after reaching $61.72 \%$ in 2000 .

Figure 9 shows the spatio-temporal evolution of urban populations of Belt and Road countries for the period 1950-2050. In 1950, other than a few European countries, urbanization in most Belt and Road countries was still in the initial stage, with only 13 countries having an urban population greater than 50\%. By 2015, two-thirds of the Belt and Road countries had urban populations above $50 \%$, and by 2050 , that proportion is expected to rise to $92 \%$ of the countries. There is significant spatial differentiation in the levels of urbanization of Belt and Road countries. Looking at the different regions, the levels of urbanization of countries in West Asia and North Africa, as well as of China, Russia and Mongolia, increase relatively quickly over the century (except Egypt and Yemen); the levels of urbanization of countries in Central Asia and South Asia increase relatively slowly, and the urban populations of the majority of countries in these two regions are still below $60 \%$ by 2050 ; and there is a relatively large difference in the levels of urbanization of different countries in Southeast Asia and Eastern Europe.
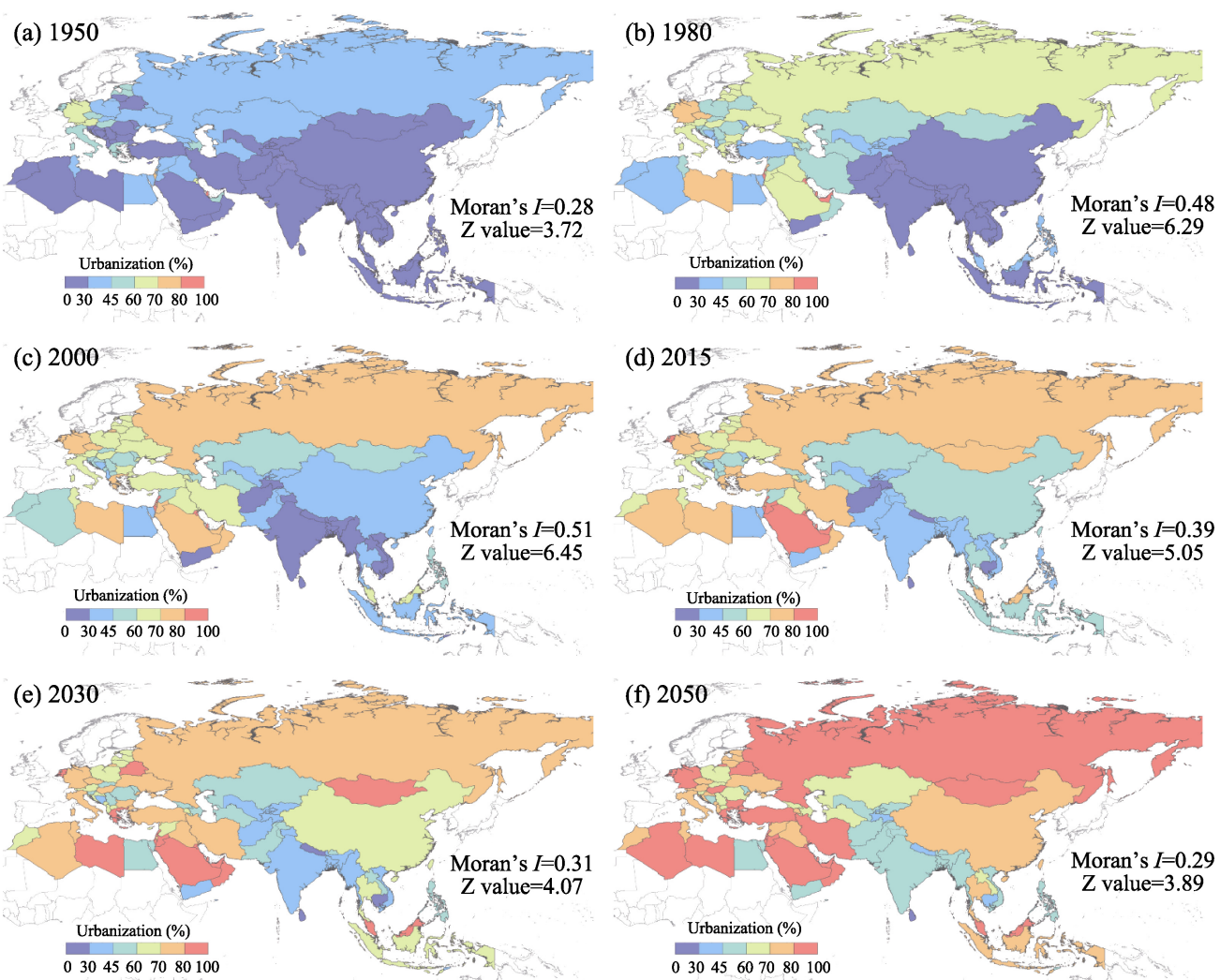

Figure 9 Spatio-temporal evolution of urban populations of Belt and Road countries 1950-2050 
Moreover, taking into account the large differences in the areas of different countries, with the help of the ArcGIS10.2 platform, the Contiguity Edges Only option was selected to calculate the Moran's I value of the urbanization of Belt and Road countries for different years (see Figure 9). The results show that the Moran's $I$ Index values are all greater than 0 at a significance level of $1 \%$, indicating that there is significant spatial dependence in the urban populations of different countries. In other words, urban populations as a proportion of total populations are more similar for adjacent countries, which is consistent with the principle of "macro-scale differences and regional-scale similarities." The Moran's $I$ and $\mathrm{Z}$ value display an upward trend for the period 1950-2000, which indicates increasing spatial agglomeration. The Moran's $I$ and $Z$ value display a downward trend for the period 2000-2050, which indicates a decline in the degree of dependence in terms of urbanization levels between neighboring countries.

\subsection{Analysis of spatio-temporal patterns in national net migration rates}

Immigration between countries includes migrants who are well-educated or rich and move in order to better their economic and social circumstances, as well as those that move to escape war or political turmoil. Outflows of the former leads to a loss of human resources and wealth from a country, while the latter will add to social instability in the receiving country. As Figure 10 shows, Belt and Road countries experience an overall population outflow for the period 1950-2050, which is largely related to the fact that many of the countries in the study area are developing countries and the frequency of wars and conflicts in those regions is relatively high. Net migration in Belt and Road countries for the period 1950-1955 was $-502,000$. This population outflow surged in the 1990s and peaked in the period 2005-2010 (at 11.07 million for the five-year period). This was mainly due to several regional wars in the Middle East. It is expected that by 2050 net migration in Belt and Road countries will be -6.7 million; however, Russia, Germany, Italy, the UAE, Qatar and a small number of other countries will have a long-term net increase in migration. Regardless of whether the Belt and Road regions as a whole experienced a positive or negative net migration rate from 1950 to the present, it is clear that as the process of globalization has accelerated, international migration has become easier and more common.

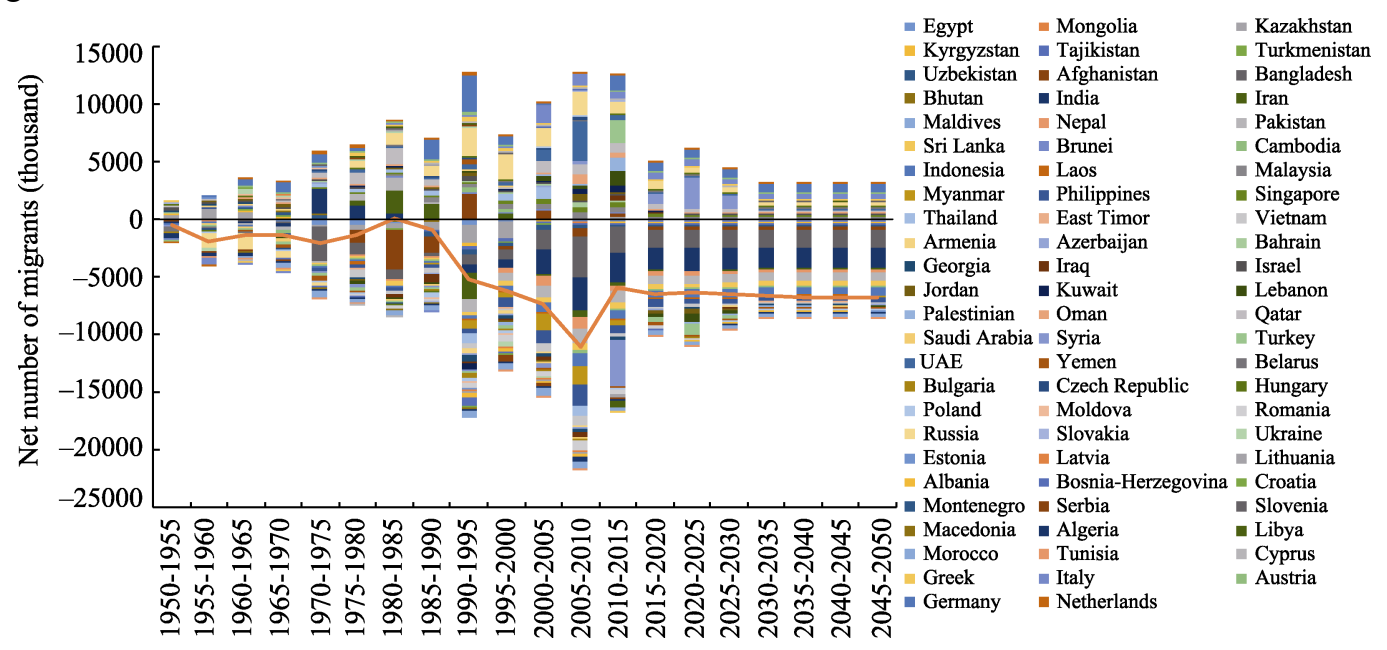

Figure 10 Changes in migration of Belt and Road countries 1950-2050 
Looking at the period 2010-2015 only (Figure 11), the Belt and Road regions as a whole had negative net migration, with a net outflow of 5.97 million for the five-year period. Of the 75 Belt and Road countries, 44 had negative net migration, and 31 had positive net migration. Syria and Libya experienced population outflows of 4.03 million and 500,000 respectively due to the effects of war, giving them the largest net outflows. India, Bangladesh, China and Pakistan also had net population outflows of over 1 million each for the five-year period. The countries with the largest net population inflows were Palestine $(6.52 \%)$ and Lebanon (4.91\%), each with more than 1.2 million immigrants. Turkey, Germany and Russia also had net population inflows of more than one million people each.

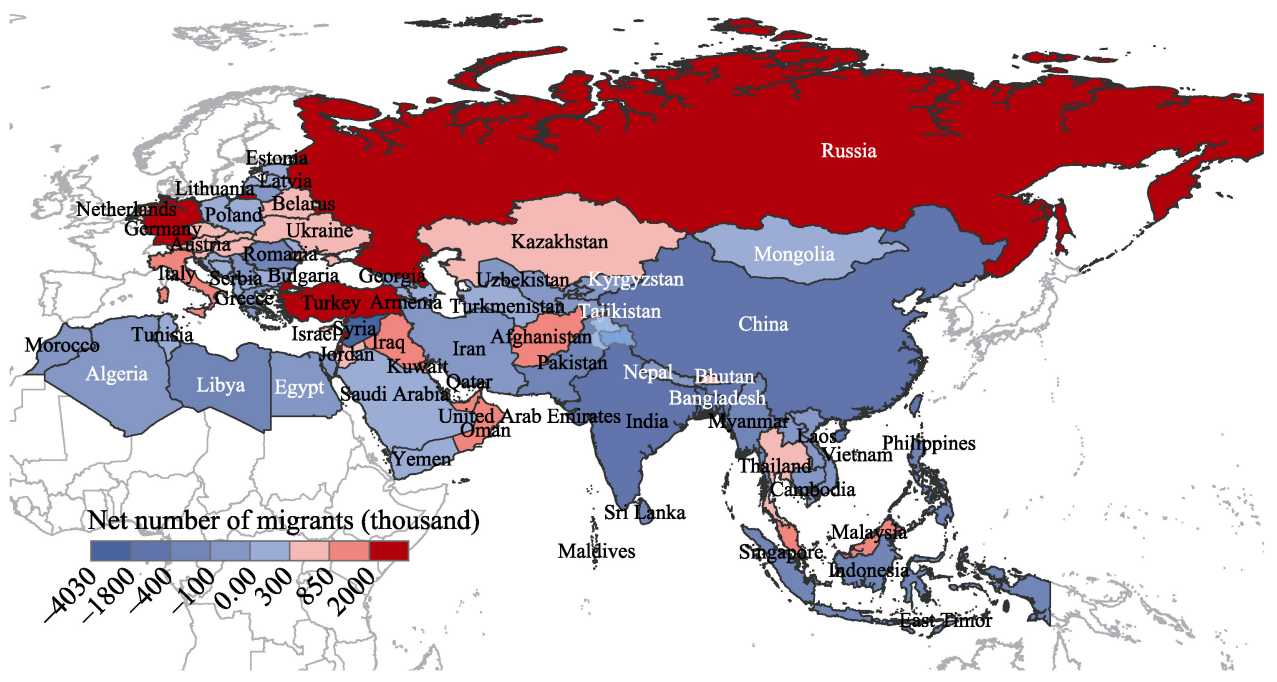

Figure 11 Spatial differentiation of net migration in Belt and Road countries 2010-2015

\section{Identifying future population and urbanization hotspots in Belt and Road countries}

Looking at future population and urbanization trends in Belt and Road countries, the UN Population Division's forecasts were used, first of all, to identify population growth hotspots for the period 2030-2050. Figure 12a shows the expected population growth of each country between 2015 and 2030. The country with the highest population growth is India, with an increase of 193.9 million, followed by China, Pakistan and Indonesia, with increases of 51.7 million, 43.6 million and 47.8 million, respectively. West Asia and North Africa are other population growth hotspots. As shown in Figure 12b, population growth hotspots are largely the same for the period 2015-2050, except for China, whose population growth will move into negative growth after its total population reaches 1.45 billion in 2030. By 2050, China will have changed from a population hotspot to a population "coldspot."

Figure 13 shows urban population growth for Belt and Road countries and regions for five-year periods between 1950 and 2050. It can be seen that there are significant differences in the urban population growth and changes of different regions. China's urban population, for example, constantly increases up to 2020, but once its birth rate falls, its urban population growth will stabilize and then begin to fall as well. South Asia's urban population 
growth constantly increases and is set to overtake China's urban population growth in 2030. Southeast Asia and West Asia will have average annual urban population growth of 6 million over the next 35 years, although growth will decrease slightly over time. In the latter half of the last century, Europe had average annual urban population growth of 2.5 million, but in the first half of the 21 st century, its urban population will remain basically stable. North Africa will have stable annual urban population growth in the future. Central Asia and Russia will experience very little urban population growth.

(a) Population growth hotspot, 2015-2030

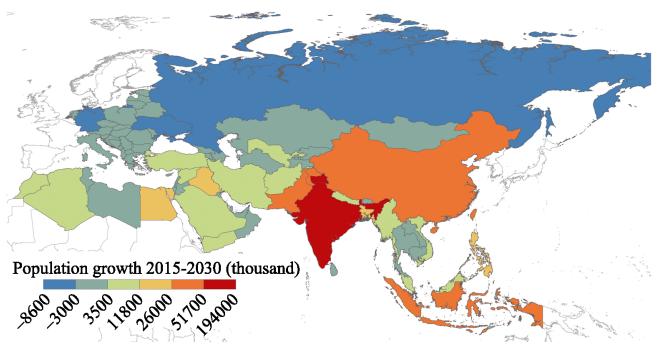

(b) Population growth hotspot, 2015-2050

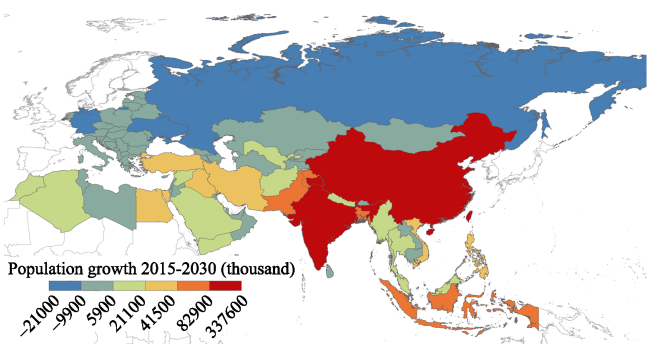

Figure 12 Distribution of population growth hotspot countries along the Belt and Road

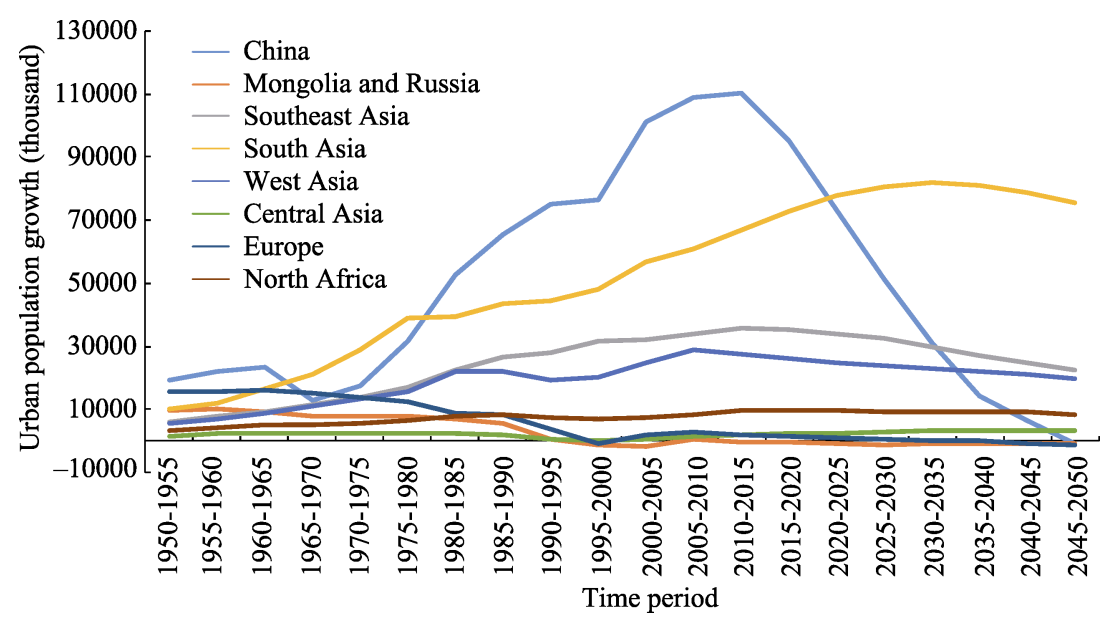

Figure 13 Evolution of urban population growth of Belt and Road regions 1950-2050

Because the UN Population Division's forecasts for specific urban populations only run up to 2030, this study focuses on future levels of urbanization and changes in the populations of megacities for the period 2015-2030. Figure 14 shows changes in the urbanization rate of each Belt and Road country over 15 years from 2015 to 2030, highlighting urbanization hotspots. Countries with the fastest urbanization rate, of over 10 percentage points, include Thailand, China, Laos and Albania. They are followed by Bangladesh, Vietnam, Indonesia, Myanmar, Mongolia, Pakistan, Afghanistan and Malaysia, with an urbanization rate of 7-10 percentage points. Urbanization "coldspots" for the period 2015-2030 include Kuwait, Cyprus, Qatar, Estonia and Armenia, as they each have an urbanization rate below 1\%.

There were 293 cities with populations above 1 million in Belt and Road countries in 2015, and there are forecast to be 377 by 2030, an increase of 84 in 15 years. Of those, 43 will be in China, with many of the others located in India, Indonesia and the eastern Mediterranean. 


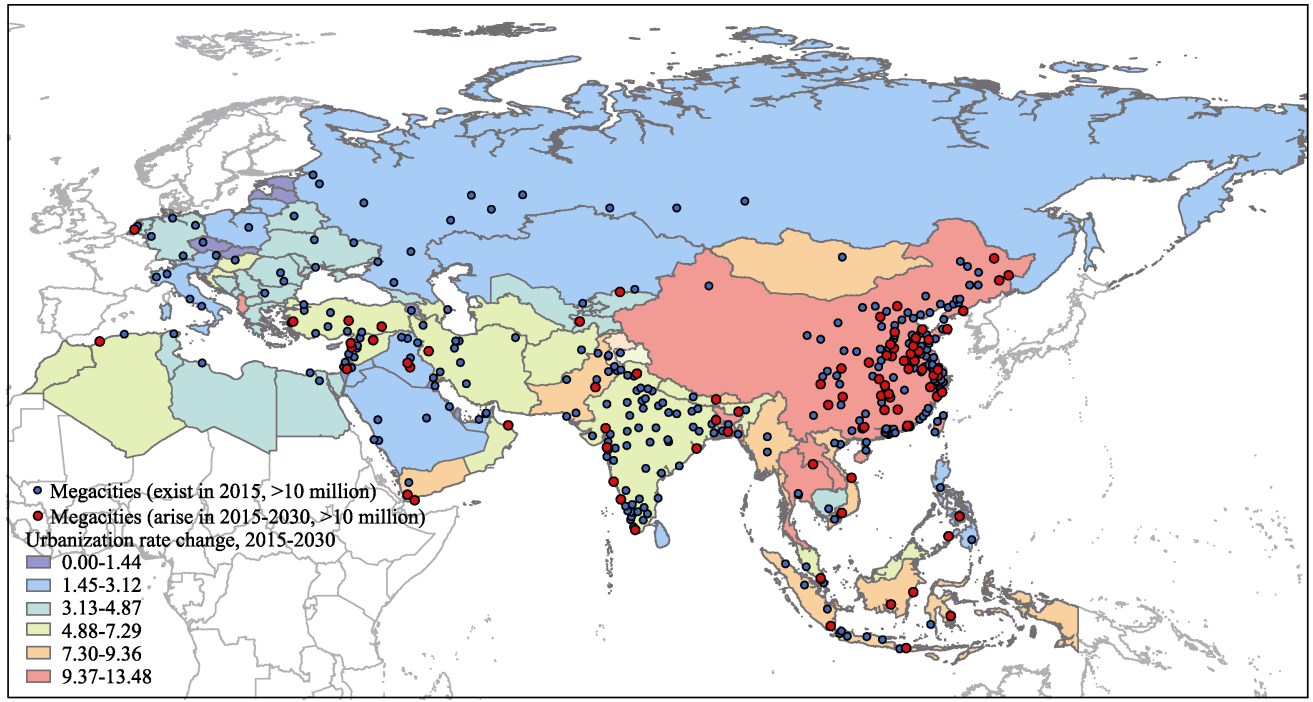

Figure 14 Urbanization hotspots and distribution of cities with populations over 1 million

\section{Conclusions}

This paper analyzed the spatio-temporal evolution characteristics of population and urbanization in 75 countries located along the Silk Road Economic Belt and the 21st-century Maritime Silk Road for a hundred-year period covering the past, present and future, identifying future population growth and urbanization hotspots. The main conclusions are as follows:

(1) In 2015, the total population of the 75 Belt and Road countries accounted for $65.98 \%$ of the world's population; their population density was 88.26 people per $\mathrm{km}^{2}$; their average population growth rate was $1.13 \%$; their average level of urbanization was $53.5 \%$; and they had negative net migration as a whole.

(2) There are significant spatial differences in the population and urbanization trends of Belt and Road countries. In 2015, the total population of the seven Belt and Road countries with populations over 100 million accounted for two-thirds of the study area's population; the majority of Belt and Road countries in Europe, South Asia and Southeast Asia had high population densities, whereas most countries in Central Asia, North Africa and West Asia, as well as Russia and Mongolia, had low population densities; the majority of countries in South Asia, Southeast Asia, Central Asia, West Asia and North Africa had rapid population growth, whereas many countries in Europe had negative population growth; and 44 Belt and Road countries are in the acceleration stage of urbanization, 26 are in the terminal stage of urbanization, and just five countries have an urban population lower than $30 \%$, putting them in the initial stage of urbanization.

(3) From 1950 to 2050, the mean center of the study area's population is consistently located in the border region between India and China. Prior to 2000, the trajectory of the mean center was from northwest to southeast, but from 2000 it is on a southward trajectory, as the population of the study area becomes more concentrated. Between 1950 and 2015 the total populations of European countries and Russia and Mongolia did not change considerably; population growth in Central Asia, West Asia and North Africa gradually accelerated; and 
China, South Asia and Southeast Asia had the fastest population growth in the study area. Future population growth hotspots are predicted to be in South Asia, West Asia and Southeast Asia. Hotspot countries for the period 2015-2030 include India, China, Pakistan and Indonesia, though China's population will move into negative growth after 2030. Population inflows and outflows increased between 1950 and the present, indicating that international migration has become easier and more common.

(4) The urban population of Belt and Road countries increased from $22 \%$ in 1950 to $49 \%$ in 2015 , and it is expected to gradually catch up with the world average, reaching $64 \%$ in 2050. In 1950, except for a few European countries, urbanization in most Belt and Road countries was still in the initial stage, with only 13 countries having an urban population greater than $50 \%$. By 2015 , two-thirds of Belt and Road countries had urban populations above $50 \%$, and by 2050 , that proportion is expected to rise to $92 \%$ of countries. The urban populations of China, Mongolia, Iran, Turkey, Malaysia and others change significantly during the period 1950-2050, with an average increase of over 60 percentage points, to all having urban populations over $70 \%$ and reaching the terminal stage of urbanization by 2050 . The pace of urbanization in India, Bangladesh, Pakistan and the Philippines is relatively slow, and their levels of urbanization are expected to remain below $60 \%$ by 2050 . The different levels of urbanization seen in different countries display significant spatial dependency, and in the hundred-year period under consideration, this dependency first increases before eventually weakening.

(5) Urbanization hotspots for the period 2015-2030 include Thailand, China, Laos and Albania, all of which will increase by 10 percentage points. Urbanization "coldspots" for the same period include Kuwait, Cyprus, Qatar and Estonia, as they each have an urbanization rate below 1\%. There were 293 cities with populations over 1 million in Belt and Road countries in 2015, and there are forecast to be 377 by 2030. Of those, 43 will be in China, with many of the others located in India, Indonesia and the eastern Mediterranean.

This paper is an empirical analysis of population and urbanization characteristics of Belt and Road countries using data from the UN Population Division, and its conclusions can act as a reference for Chinese companies looking to invest overseas, cross-border infrastructure projects and people-to-people exchanges. Nevertheless, what differences exist in the quality, paths and drivers of urbanization in different countries? What impact will implementation of the Belt and Road Initiative have on the populations and urbanization of Belt and Road countries? How can China's successful urbanization model and experience be exported to Belt and Road countries? As the scale of urbanization increases in Belt and Road countries in the future, these questions will become the foci of future research.

\section{References}

Chen M, Ye C, Zhou Y, 2014. Comments on Mulligan's "Revisiting the urbanization curve". Cities, 41(41): S54-S56.

Chen W G, Guo Q, 2016. China's investment potential estimation and location selection of The Belt and Road countries. Macroeconomics, (9): 148-161. (in Chinese)

Cheng H, Sun J L, Dong S C et al., 2016. Informatization patterns and strategy of The Belt and Road. Bulletin of Chinese Academy of Sciences, 31(6): 656-662. (in Chinese)

Fan Z B, Zhang R H, Liu X T et al., 2016. China's outward FDI efficiency along the Belt and Road: An 
application of stochastic frontier gravity model. China Agricultural Economic Review, 8(3): 455-479.

Fang C, Liu H, Li G et al., 2015. Estimating the impact of urbanization on air quality in China using spatial regression models. Sustainability, 7(11): 15570-15592.

Ferdinand P, 2016. Westward ho-the China dream and 'One Belt, One Road': Chinese foreign policy under Xi Jinping. International Affairs, 92(4): 941-957.

Guo J E, Wang S B, Xia B, 2015. Study on the current situation and path of energy cooperation in the Silk Road Economic Belt. Economic Review, (3): 88-92. (in Chinese)

Hennig B D, 2013. Rediscovering the World: Map Transformations of Human and Physical Space. Springer.

Hong P, 2016. Jointly Building the 'Belt and Road' towards the Sustainable Development Goals. New York: Social Science Electronic Publishing.

Howard K W F, Howard K K, 2016. The new "Silk Road Economic Belt" as a threat to the sustainable management of Central Asia's transboundary water resources. Environmental Earth Sciences, 75(11): 1-12.

Li Z H, Wang J L, Zhao Z P et al., 2014. Eco-environment patterns and ecologycal civilization modes in the Silk Road Economic Zone. Resources Science, 36(12): 2476-2482. (in Chinese)

Liang Q, Wu X S, 2016. Study on influencing factors of bilateral trade among the countries along the Belt and Road: An empirical test based on the expansion gravity equation. Economist, (12): 69-77. (in Chinese)

Liu H M, Fang C L, Ren Y F, 2016. Logistics industry and cross-border electric business of Sino-Kazakhstan cooperation demonstration zone in Silk Road Economic Belt. Arid Land Geography, 39(5): 951-958. (in Chinese)

Liu H Z, Cai X S, 2016. Study on bilateral trade costs of China with the Belt and Road countries. Economist, (7): 92-100. (in Chinese)

Liu W D, 2015. Scientific understanding of the Belt and Road Initiative of China and related research themes. Progress in Geography, 34(5): 538-544. (in Chinese)

Liu W D, Tian J, Ou X, 2017. Strategic Studies on the Belt and Road. Beijing: The Commercial Press. (in Chinese)

Pan J H, Hu Y X, Dong X F, 2016. Spatial-temporal evolution of economic disparity for the Silk Road Economic Zone. Economic Geography, 36(1): 10-17. (in Chinese)

Song G, Yang J, 2016. Measuring the spatiotemporal variation and evolution of transport network of China's megaregions. Journal of Geographical Sciences, 26(10): 1497-1516.

Sun Z L, Li X D, 2016. Agricultural trade situation and agricultural economic trade cooperation prospects between countries along The Belt and The Road and China. Intertrade, (11): 38-42. (in Chinese)

Tao L, Yuan J, Q I, Cao G et al., 2015. Spatial patterns, driving forces, and urbanization effects of China's internal migration: County-level analysis based on the 2000 and 2010 censuses. Journal of Geographical Sciences, 25(2): 236-256.

Tian Z, Xu D M, 2016. The investment efficiency and countermeasures of The Belt and Road along the country. Economic Review, (5): 84-89. (in Chinese)

Yang D L, Wang J X, Li X L, 2016. Report on the evaluation of development level of information infrastructure of countries along The Belt and Road. E-Government, (9): 2-15. (in Chinese)

Zhang J, Lei H, Wang Y F et al., 2016. Comparision of transportation infrastructure investment efficiency of countries along The Belt and Road. Statistics \& Decision, (19): 61-63. (in Chinese)

Zhao M, 2016. The Belt and Road Initiative and its implications for China-Europe relations. The International Spectator, 51(4): 109-118.

Zhao M Y, Dong S C, Wang Z et al., 2016. Assessment of countries' security situation along the Belt and Road and countermeasures. Bulletin of Chinese Academy of Sciences, 31: 689-696. (in Chinese)

Zeng X H, 2016. The geopolitical imaginations of the "One Belt, One Road" initiative and regional cooperation. World Economics and Politics, (1): 46-71, 157-158. (in Chinese)

Zhu Y J, 2016. Pay attention to the religion culture of countries along The Belt and Road: The necessary evidence of Chinese enterprises "Going Out". Chinese Religion, (9): 42-43. (in Chinese)

Zou J L, Liu W D, 2016. Trade network of China and counties along "Belt and Road Initiative" areas from 2001 to 2013. Scientia Geographica Sinica, 36(11): 1629-1636. (in Chinese) 